\title{
Unfinished Reform of the Institutions Enforcing UK Competition Law
}

\author{
Bruce Lyons \\ Centre for Competition Policy \& School of Economics \\ University of East Anglia
}

\section{CCP Working Paper 21-01}

This version: August 2020

The period since 1998 has seen major changes in competition law, including: public interest was replaced by promotion of competition as the primary duty; anticompetitive agreements and abuse of a dominant position were prohibited, with significant penalties for breach; and the Minister withdrew from case decisions, making the institutions determinative. There were also major organisational changes, including merger of the OFT and CC to form the CMA, and establishment of the CAT as a specialist appeals body. I consider the evolution of these institutions from the perspective of how they frame and influence the quality of first instance determinations. Institutions are hostages to their history, and I trace some of the problems faced by the CMA to its institutional roots. New challenges beyond its control are also identified. Reform is needed. Some of the CMA's suggestions for legislation are misguided, particularly in replacing its competition duty with 'the consumer interest', and reducing the standard of review by the CAT without reform of the CMA. Alternative proposals are considered, including a potential change to a prosecutorial system. I argue that genuinely independent decision-making within the CMA should be preferred and would permit a more limited standard of review.

\section{Contact Details:}

Bruce Lyons b.lyons@uea.ac.uk 


\section{Unfinished Reform of the Institutions Enforcing UK Competition Law}

\section{Bruce Lyons}

Professor of Economics

School of Economics and Centre for Competition Policy

University of East Anglia

\section{$\underline{\text { Abstract }}$}

The period since 1998 has seen major changes in competition law, including: public interest was replaced by promotion of competition as the primary duty; anticompetitive agreements and abuse of a dominant position were prohibited, with significant penalties for breach; and the Minister withdrew from case decisions, making the institutions determinative. There were also major organisational changes, including merger of the OFT and CC to form the CMA, and establishment of the CAT as a specialist appeals body. I consider the evolution of these institutions from the perspective of how they frame and influence the quality of first instance determinations. Institutions are hostages to their history, and I trace some of the problems faced by the CMA to its institutional roots. New challenges beyond its control are also identified. Reform is needed. Some of the CMA's suggestions for legislation are misguided, particularly in replacing its competition duty with 'the consumer interest', and reducing the standard of review by the CAT without reform of the CMA. Alternative proposals are considered, including a potential change to a prosecutorial system. I argue that genuinely independent decision-making within the CMA should be preferred and would permit a more limited standard of review.

Chapter 8 of:

The UK Competition Regime: A Twenty-Year Retrospective

Angus MacCulloch, Barry Rodger and Peter Whelan (Editors)

Planned publication by OUP in 2021

Version: 16 August 2020 


\section{Introduction 1}

Institutions are where decisions are made. They frame how decisions are made and determine who makes them. Some of these decisions are strategic, such as the allocation of resources and prioritisation of cases. Other decisions are case specific and adjudicative (e.g. merger prohibition or finding abuse of dominance). Legislation may detail the powers of decision and the broad organisational structure in which they are made, but much remains dependent on the internal institutional culture. Institutions provide the foundation on which a competition regime can either build solidly or crack and subside. Foundations must be appropriate to the structure of competition law being built, and in the UK that structure has changed fundamentally since 1998. The institutions have also changed, but too little attention has been placed on how the changes in competition law require complementary changes in the institutions.

It is easy to list the organisational changes of the last two decades. The Monopolies and Mergers Commission (MMC) became the Competition Commission (CC) in 1999 following the Competition Act 1998 (CA98); an independent Competition Appeals Tribunal (CAT) was established in 2003 following the Enterprise Act 2002 (EA02), and the Office of Fair Trading (OFT) and the CC merged to become the Competition and Markets Authority (CMA) in 2014 following the Enterprise and Regulatory Reform Act 2013 (ERRA13). ${ }^{2}$ There were also new competition powers and reorganisations for the specialist sector regulators. The overall effect was to raise the penalties for transgressing competition law at the same time as the competition agencies were taking the power of decision away from the elected Secretary of State (SoS). ${ }^{3}$

The aim of this chapter is to understand not just the organisational changes set out above, but the ways of working, conventions, appointments, decision-making procedures and safeguards that give the organisational skeleton its functionality. It is these factors, alongside any formal rules and organisations, that North would consider the institutions of the UK competition regime. ${ }^{4}$ Regulatory agencies and formal rules can be created, renamed and redesigned by political fiat, but operational decisions remain strongly influenced by the continuing culture:

"Institutions typically change incrementally rather than in discontinuous fashion...

Although formal rules may change overnight as a result of political or judicial decision,

\footnotetext{
${ }^{1}$ I thank the editors and particularly Amelia Fletcher for insightful comments on an earlier draft. All opinions and errors are solely those of the author.

${ }^{2}$ Membership of the EU has also affected the UK institutions, particularly since 2004 with powers to enforce Articles 101 \& 102 TFEU under Regulation 1/2003 (although the European Commission retained the power to return a case to Brussels), and participation in the European Competition Network (ECN). More recently, the European Union (Withdrawal Agreement) Act 2020 (EUWAA20) allows the UK to investigate mergers and antitrust issues which affect multiple Member States, which were previously reserved for the European Commission.

${ }^{3}$ The relevant SoS is the head of the 'business' ministry, which was the Department of Trade and Industry (DTI, 1970-2007), Department for Business, Enterprise and Regulatory Reform (2007-09), Department for Business, Innovation and Skills (BIS, 2009-16), and Department for Business, Energy and Industrial Strategy (BEIS, since 2016).

${ }^{4}$ Douglass C. North, Institutions, Institutional Change and Economic Performance (1990) Cambridge UP.
} 
informal constraints embodied in customs, traditions, and codes of conduct are much more impervious to deliberate policies." 5

So, it is necessary to delve back to their origins to understand the current UK institutions, their strengths, and their weaknesses.

In section 2, I set out what matters in institutional design and how success should be measured. Section 3 provides a short history of the very different institutional cultures in the competition agencies inherited from the twentieth century. Section 4 highlights how the new century brought a new economic approach to competition policy alongside the new powers of remedy, penalty and decision in CA98 and EA02. I examine how these were addressed in the OFT, CC and CAT. Section 5 considers the compromise embodied in the contrasting institutional cultures within the newly merged CMA brought about by ERRA13. In Section 6, I highlight the very substantial new challenges for the CMA going forward from 2020, examine the CMA's own flawed agenda for reform, and suggest a more robust way forward. Section 7 concludes.

\section{What matters in institutional design and performance?}

An effective institutional arrangement cannot simply pick-and-mix because changing one part of that system has ramifications elsewhere. There is no research that identifies a uniquely optimal system, but there is a consensus amongst scholars of the features that matter. ${ }^{6}$

\subsection{Mandate}

Competition authorities are given a range of responsibilities and legislation to implement. They also have advisory and advocacy duties. The portfolio of legal instruments usually includes powers concerning agreements between firms, the behaviour of a single firm (or group of firms) with market power, and mergers. UK competition law also provides for market investigations with strong potential remedies including the ability to cap prices or order a firm to be broken up. Consumer law enforcement and, prospectively, the review of state aid are also the CMA's responsibility, and sector regulators have both direct regulatory powers and concurrent powers for competition enforcement. There is a basic organisational trade-off between clear focus on a range of activities requiring similar skills (e.g. analysis of the competitive effects of business strategies, or industry knowledge), as against resource-

\footnotetext{
5 Ibid 6.

${ }^{6}$ This section draws on the following: William E. Kovacic, Rating the Competition Agencies: What Constitutes Good Performance?, 16 Geo. Mason L. J.(2009) 903; Michael J. Trebilcock and Edward M. lacobucci, Designing Competition Law Institutions: Values, Structure, and Mandate, 41, Loy. U. Chi. L. J., 455 (2010); Eleanor M. Fox, Antitrust and Institutions: Design and Change, 41, Loy. U. Chi. L. J., 473 (2010); Philip Lowe, The Design of Competition Policy Institutions for the $21^{\text {st }}$ Century - The Experience of the European Commission and DG Competition, Competition Policy Newsletter, European Commission (2008) 1; Eleanor M. Fox and Michael J. Trebilcock, The Design of Global Law Institutions: Global Norms, Local Choices, 2013, Introduction; Joshua Wright and Angela Diveley, 'Do Expert Agencies Outperform Generalist Judges? Some Preliminary Evidence from the Federal Trade Commission' (2012) Journal of Antitrust Enforcement 1-22; Frederic Jenny 'The Institutional Design of Competition Authorities: Debates and Trends', in: Competition Law Enforcement in the BRICS and in Developing Countries. Legal and Economic Aspects. Cham (Switzerland): Springer, 2016, 1.
} 
sharing and coordination across a wider, more diverse range of responsibilities (e.g. competition and consumer protection).

Competition authorities are also given overarching goals in the form of legal duties. For example, there may be a primary duty to act in the public interest, or to promote competition, or to protect consumers. Sparse legal wording is open to interpretation, so the agency may choose to express its mission in language that helps its staff focus on priorities, or which is better understood by other stakeholders. For example, the CMA's mission is to make markets work in the interests of consumers, businesses and the economy. ${ }^{7}$ The mission can be influential in prioritising cases, motivating staff and gaining public support.

A third dimension of their mandate is the extent to which a competition authority is allowed to make decisions without reference to the minister. ${ }^{8}$ Even when a minister is not the decision-maker, politicians can exert general influence through budget setting, parliamentary scrutiny, the approval of senior appointments (and, importantly, reappointments), and informal pressure (e.g. conversations between the agency head and the minister). The degree of independence of those making first instance decisions is greatly enhanced if their continuation in that role cannot be influenced by the determinations they make. This can be achieved by either appointment until retirement or fixed term appointments without possibility of renewal.

\subsection{Organisational design and decision-making}

The institutions of any competition regime frame a wide range of different types of decision, including: budget allocation; case selection; case investigation and analysis; first instance determination of whether business behaviour is anti-competitive and, if so, what fines and/or remedies to apply; and appeal/review of contested determinations. The way these decisions are organised can have a profound effect on both the efficiency and the fairness of a competition regime.

Trebilcock and lacobucci identify three organisational models in which these decisions are made. ${ }^{9}$ The bifurcated agency model has two specialised agencies, each with investigative resources, the first focusing on case selection ('phase $1^{\prime}$ ), and the second completing the investigation and adjudicating ('phase 2'). This was the UK structure for markets and mergers with the OFT and CC prior to ERRA13. The integrated agency model brings case selection, investigation and adjudication under one roof, as with the CMA (also with the OFT for CA98 prohibitions). Both agency models are naturally inquisitorial, with the adjudicating body aiming to adopt a balanced view. In contrast, a bifurcated judicial model has a specialised investigative agency, which brings each case for adjudication by an independent tribunal or court. This prosecutorial system is periodically proposed as an alternative model for UK

\footnotetext{
${ }^{7}$ See section 5.1.1.

${ }^{8}$ Politicians are often happy to reduce their operational workloads and shift responsibility for decisions that may be unpopular with certain interest groups. For evidence that political independence enhances the quality of a competition regime, see Christel Koop and Chris Hanretty, 'Political Independence, Accountability, and the Quality of Regulatory Decision-Making' Comparative Political Studies 2018, Vol. 51(1) 38 -75.

${ }^{9}$ Trebilcock and lacobucci (n 6). See also Michael Trebilcock \& Edward lacobucci, Designing Competition Law Institutions, 25 World Competition, 361, 372-80 (2002).
} 
competition enforcement, with the CMA taking cases to the (renamed) CAT for first instance decisions. ${ }^{10}$

Cross-examination in court provides the characteristic challenge to evidence and analysis in a prosecutorial system. An inquisitorial system must build challenge into its own decisionmaking processes, and provide access for the parties to the decision maker. A lone decisionmaker can act decisively and with speed, but he or she can find it difficult to shift from an initial position. Group decision-making is not necessarily better if its members are of unequal status in a hierarchy, or if all have a similar perspective, or if the same individuals are involved at successive stages of case determination and so vulnerable to confirmation bias. ${ }^{11} \mathrm{~A}$ group with a greater diversity of skills and experience is more likely to start from different positions and has a greater need to debate and test positions.

\subsection{Rights of appeal}

Parties subject to an adverse determination must have the right of review or appeal. The right of third-party appeal provides a check on under-enforcement. A central issue is the degree of scrutiny conducted by the appeal court or tribunal. Judicial review addresses the lawfulness of the decision - whether it is illegal, irrational, procedurally inappropriate or disproportionate. A merits appeal additionally addresses the correctness of the decision - it is less deferential to the first instance decision, and the appeals body may substitute its own determination.

The level of review/appeal is a matter of common law, HRA98 and legislation (e.g. CA98 requires merits review for the prohibitions). ${ }^{12}$ There are generally two sets of factors to be balanced. ${ }^{13}$ First, the seriousness of the consequences of the first instance decision. This includes fines and remedies affecting property-rights (e.g. price controls, divestiture/breakup of a firm), as well as the reputational damage associated with quasi-criminality. Second, the expertise, processes and independence of decision-making behind the first instance determination, especially relative to that of the appeals body.

\subsection{Evaluation of performance}

\footnotetext{
${ }^{10}$ See Department for Business, Innovation and Skills (BIS), A Competition Regime for Growth: A Consultation on Options for Reform, March 2011; Renato Nazzini, 'A Reform Too Few or a Reform Too Many: Judicial Review, Appeals or a Prosecutorial System under the UK Competition Act 1998?', Journal of Antitrust Enforcement, 2020, 1-35.

${ }^{11}$ See Damien J. Neven 'Competition Economics and Antitrust in Europe', Economic Policy, October 2006 pp.741-791; William E. Kovacic \& James C. Cooper, Behavioral Economics and Its Meaning for Antitrust Agency Decision Making, 8 J.L. Econ. \& Pol'y 779 (2012). The latter discuss the evidence and foundations of confirmation bias, which Neven labels 'prosecutorial bias'.

${ }^{12}$ Nazzini (n20). The right to a fair trial is enshrined in Article 6 of the European Convention for the Protection of Human Rights (1950), brought into effect in the UK by the Human Rights Act 1998. Note editors corss ref Andreangeli.

${ }^{13}$ A review on merits "will accord appropriate respect to the decision of the lower court. Appropriate respect will be tempered by the nature of the lower court and its decision-making process. There will also be a spectrum of appropriate respect depending on the nature of the decision of the lower court which is challenged." Dupont de Nemours v Dupont (2003) EWCA Civ 1368, para 94.
} 
Performance appraisal is a prerequisite for understanding how a competition regime can be improved. The problem is how to do this systematically. It is easy enough to write down a list of theoretically desirable indicators: elimination of consumer detriment; appropriate choice of cases for precedent; speed, efficiency and consistency of decisions; procedural fairness and rights of defence; quality of decisions and robustness to appeal; deterrence achieved by the above; and effective advocacy. It is another matter to appraise success in these dimensions. A number of indicators have been proposed.

The number of decisions is suggestive, not least because decisions are necessary for precedent and deterrence, but this conveys nothing about each decision's quality or wider importance. ${ }^{14}$ The number of successful appeals may appear to provide a negative indicator of the quality of individual decisions, but this is fundamentally biased - prohibitions are more likely to be appealed than clearances, and weak agencies do not take controversial decisions. Careful ex-post reviews of individual cases are useful indicators, but they are expensive to conduct and provide no cross-organisational comparisons. ${ }^{15}$ Similar problems affect other case-centric measures of performance.

An alternative methodology is to focus on the institution as a whole and its coherence along the dimensions set out in sections 2.1-2.3. This approach facilitates greater sensitivity to the less quantifiable nuances of institutional design, but it can only identify broad lessons given the range of dimensions of design and the international diversity of institutions. ${ }^{16}$

Further insight at the institutional level can be gained through peer assessment of reputation. Kovacic explains the benefits:

“Perceptions of a competition agency's quality directly influence judicial decisions about whether to defer to the agency's positions, legislative decisions about the agency's budget and statutory authority, the willingness of companies to comply with laws entrusted to the agency's enforcement, and the agency's ability to hire and retain capable staff. A competition agency that enjoys an excellent brand is also likely to inspire citizen confidence in government by showing that public institutions truly 'work'."17

Each of the above approaches has weaknesses, but together they become persuasive so I draw on each in the following sections appraising the UK institutions.

\footnotetext{
${ }^{14}$ Kovacic, W. E., Hollman, H. \& Grant, P., 2011. How Does your Competition Agency Measure Up?, European Competition Journal, 7(1), 25.

${ }^{15}$ The CMA conducts an externally validated annual impact assessment of its work, based on the estimates of consumer benefit it calculates for each completed case. See section 5.3.

${ }^{16}$ The most detailed study along these lines compare nine different jurisdictions using criteria of efficiency and fairness. See Fox and Trebilcock, 2013 (n 6).

17 William Kovacic 'Rating the Competition Agencies: What Constitutes Good Performance?' (2009) Geo.

Mason L. Rev. 16:4, 903.
} 


\section{Institutional cultures inherited from the $20^{\text {th }}$ century}

\subsection{The 'Monopolies Commission' and Restrictive Practices Court}

Fox argues that "[a] jurisdiction's first design is its most important design". ${ }^{18}$ The UK's first competition agency was the Monopolies and Restrictive Practices Commission (MRPC). ${ }^{19}$ It was established in 1949 to investigate and report on the public interest of any monopolies or restrictive practices referred to it by the Secretary of State (SoS), who would then decide on action in the light of the report. It was fundamentally an investigative body, writing reports with recommendations for the minister to decide.

The MRPC consisted of a panel of members with a Chairman who was primus inter pares in decision making. Both were appointed by the SoS. Members sat as a group and were all parttime. The Chairmen from 1954 to 1993 were all Queen's Counsel, but the members included people from business, finance, public sector and universities. ${ }^{20}$ The institutional longevity of this decision-making structure was such that half a century later, members were "recognisably similar people, doing a recognisably similar job, to their predecessors appointed in 1949". ${ }^{21}$ They were, in today's parlance, part of the gig economy, paid at a modest rate, only for the days they attended meetings, and providing a remarkably cheap source of expertise and experience.

The MRPC rapidly established an investigative procedure that was to cover all types of case. This included: the members attending site visits and informal discussions; a fact-finding stage and a formal clarification hearing with the main parties; reflection and analysis to establish a provisional view of the public interest; communicating this in writing to the parties and inviting written responses, with a further hearing to discuss these; followed by a full report. Reports were published in full, subject to excisions for business confidentiality. Apart from the public interest test, these institutional procedures remain substantially unchanged in the markets and mergers directorate of the CMA seventy years on.

The public interest was loosely defined: "The Commission shall take into account all matters which appear to them in the particular circumstances to be relevant". 22 The interpretation of public interest was decided afresh in each case with no constraint of precedent and no issuance of guidance.

In the 1940s, there was no strong presumption against either monopolies or restrictive practices, which had been seen as helpful for coordination during the crisis of World War 2 indeed, it was a period of monopoly creation under public ownership (i.e. nationalisation). Over the years, the public interest test became interpreted more narrowly on competition, but it lasted formally throughout the twentieth century.

\footnotetext{
${ }^{18}$ Eleanor M. Fox (2010) 'Antitrust and Institutions: Design and Change' Loyola University Chicago Law Journal, 41.3, Article 6.

${ }^{19}$ For the history of the MRPC and its successors in the twentieth century, I draw heavily on Stephen Wilks, In the Public Interest: Competition Policy and the Monopolies and Mergers Commission (Manchester UP 1999).

${ }^{20} \mathrm{~A}$ civil servant at the grade of Under-Secretary helped design procedures and oversee the staff support.

${ }^{21}$ Wilks (n 19) 2.

${ }^{22}$ Fair Trading Act 1973, sec 84.
} 
As the problems with cartels and other restrictive practices became apparent, the 1956 Restrictive Trade Practices Act established a Restrictive Practices Court (RPC) to adjudicate on them. They were not per se illegal, but they had to be registered and a new Registrar of Restrictive Trade Agreements could take them to the RPC. The requirement to register harmless agreements made the system administratively burdensome. ${ }^{23}$ Furthermore, the SoS could exempt agreements and the RPC had no power to impose penalties other than for contempt of court.

The MRPC was renamed the Monopolies Commission (MC) in 1956, when it lost its role in restrictive practices, and then the Monopolies and Mergers Commission (MMC) in 1973, eight years after its mandate was extended to include reporting on the public interest of mergers. ${ }^{24}$ Similarly to monopolies, the SoS referred mergers for investigation, the MC wrote its report and made recommendations, then the SoS was determinative on remedies and prohibitions. ${ }^{25}$ Looking forwards in this institutional story, the MMC would become the CC and continue with its established administrative/inquisitorial approach, panel of independent members and group decision making.

The post of Registrar and the RPC set the seeds for two new institutional lines that emerge as the OFT and CAT. The Registrar was a personalised role, albeit with a small staff to advise him and, if he could not cajole firms into dropping an agreement, he could refer the agreement to the RPC for determination. The individual Registrar, with only advisory and referral powers, would evolve into the pre-CA98 DGFT supported by OFT staff. The RPC sat, when needed, as a three-person group including a senior judicial appointment and lay members who had business or economics expertise. The character of this decision-making group is to be found in today's CAT, although the RPC was not an appeals body.

\subsection{The OFT and sector regulators}

The birth of the Office of Fair Trading (OFT) in 1973 was in economically chaotic times. ${ }^{26}$ In the same year, the Counter-Inflation Act set up a separate (and larger) Price Commission to try to control prices whilst inflation was rising to over $25 \%$ pa. Political attention in 1973 was also directed at UK accession to the EU. The government wanted to shed some burdensome operational responsibilities from the SoS and the business ministry (then named the DTI). Consideration had been given to various organisational models, including extending the mandate of the MC, but eventually it was decided to create the new role of Director-General of Fair Trading (DGFT), to be supported by a civil service staff in the form of the OFT.

\footnotetext{
${ }^{23}$ The European Commission would find much the same problem with Article 101 until the reform of Regulation 17/62 in 2003.

${ }^{24}$ Monopolies and Mergers Act 1965. In 1980, it was given a further role in investigating the efficiency of nationalised industries, which helps explain why it later became the appeals body for firms subject to decisions by the post-privatisation sector regulators.

${ }^{25}$ The European merger regulation No 4064/89 limited the MMC's role in merger control to mainly domestic mergers from 1990. By this time, 'monopoly' was defined broadly to be either a single firm with at least $25 \%$ share of supply, or parallel conduct by oligopolists (known as 'complex monopoly').

${ }^{26}$ Established under the Fair Trading Act (1973). See Wilks (n 19) ch.6, and Sir Gordon Borrie's valedictory reflections on his 16 years as DGFT in his 'Annual Report of the Director General of Fair Trading', 1991, OFT.
} 
The DGFT had duties relating to the economic interests of consumers and to competition. ${ }^{27}$ The consumer portfolio ranged from licensing debt-collectors to liaising with trading standards officers, and it took up 50\% more resources than competition. ${ }^{28}$ The competition portfolio included absorbing the role of the Registrar and advising the SoS on whether to refer a merger to the MMC. The OFT also took over from the SoS/DTI in horizon-scanning and initiating monopoly references, though the SoS retained a veto. The OFT was further responsible for implementing remedies recommended by the SoS. ${ }^{29}$

The DGFT was appointed by the SoS on renewable 5-year terms, so the system encouraged cooperation between the DGFT and SoS through the DTI. It became the practice to negotiate with businesses about their restrictive agreements, rather than challenge them before the RPC. One result was the lack of published evidence or reasoning, and so also the lack of precedent or guidance for firms. The same negotiated approach developed for mergers, with divestments in lieu of a reference to the MMC. ${ }^{30}$

As the privatisation of public utilities proceeded through the 1980s and 1990s, it became necessary to regulate the non-competitive elements of the market. This led to the establishment of a series of sectoral regulators, starting with the Office for Telecommunications in 1984. They were set up with Director Generals and in the image of the DGFT/OFT. Their roles included setting price controls and revising licence conditions (initially issued by the SoS). They could also make merger and monopoly references to the MMC, which additionally advised on appeals in relation to their regulatory decisions. ${ }^{31}$

\subsection{Inherited institutional cultures}

The second half of the twentieth century established the deep-rooted decision-making cultures into which the three major pieces of legislation of the last two decades would be fitted. The MMC was unable to initiate its own inquiries but had a powerful tradition of reporting by independent groups. The OFT and sector regulators were established under single person Director Generals, with competition powers mainly to refer to another body for determination, and a closer relationship with the SoS. The SOS/DTI was not involved in investigations but retained widespread powers to overrule both the DGFT and MMC. The RPC was required only on the few occasions when the DGFT and businesses could not agree on restrictive agreements. The substantive test for all was whether business practices were against the public interest. If they were found to be so, firms faced no significant penalty beyond being told to stop.

\footnotetext{
27 FTA73 Pt 1 sec 2.

28 OFT Annual Report 1991 Appendix K, p.83. The first two DGFTs were lawyers, including Sir Gordon Borrie QC who was a consumer protection lawyer and held the post 1976-92.

${ }^{29}$ To give a sense of relative scale, the OFT had 400 staff in 1990, the MMC had volatile staff numbers but never more than 120, and the Price Commission had 500-600 in the late 1970s.

${ }^{30}$ See Borrie (n 26) 10; Peter Freeman, Better to Travel Hopefully than to Arrive? The Reform of UK Competition Law 1991-2016, 2016, Zeeman Lecture at Regulatory Policy Institute, Oxford.

${ }^{31}$ See Wilks (n 19) 255.
} 


\section{The competition test and new powers of decision: institutional implications of CA98 and EA02}

The turn of the millennium brought a burst of reform in competition law, both in the UK and across Europe. Two transformative Acts, CA98 and EA02, brought about three fundamental changes. First, public interest was replaced explicitly by competition as the substantive test for appraising restrictive practices, monopolies and mergers. This necessitated a much sharper focus on the economic analysis. Second, anticompetitive agreements and the abuse of a dominant position were prohibited, and significant penalties were introduced for firms in breach of a prohibition. Third, the OFT and MMC became determinative, including for the new markets regime, with the SoS withdrawing from case decisions other than for narrowly defined and rare public interest exceptions. The institutions needed to evolve to take proper advantage of these changes.

\subsection{The rise of the economic approach}

While the interpretation of 'public interest' is naturally a political decision, anti-competitive effects lie in the more technical realm of economic analysis. In the 1980s, the development of a game-theoretic analysis of competitive interactions had provided a rigorous framework that could incorporate details of the market. ${ }^{32}$ New microdata and econometric techniques in the 1990s showed how the theory could be used to interpret economic evidence. ${ }^{33}$ Further interaction between academics (and their newly trained students) with competition practitioners in the 2000s facilitated the development of practical tools and guidance. Senior legal scholars in the USA had prepared the way for a more economic approach to competition analysis and the US agencies were early adopters. The intellectual conditions were right for institutions in the UK and Europe to follow suit. ${ }^{34}$

Influential appointments of academic economists to lead the UK institutions confirmed the central role of economic analysis. In 1998, Derek Morris became the first competition economist appointed Chairman of the CC, and in 2000, John Vickers was appointed DGFT. Their immediate successors were also competition economists.

\subsection{The OFT}

The core change brought about by CA98 was the move from absence of a formal presumption against restrictive agreements or monopoly practices, to the formal prohibitions against anticompetitive agreements (ch.1) and abuse of dominance (ch.2), to mirror TFEU Articles $101 \& 102$. Penalties for breach of the prohibitions were potentially substantial (up to $10 \%$ of turnover), and there were new rights of private action for damages, which further raised

\footnotetext{
32 For example, Jean Tirole, The Theory of Industrial Organization, 1988, Cambridge, MA: MIT Press; Massimo Motta, Competition Policy: Theory and Practice, (2004), Cambridge U. P.

${ }^{33}$ See Bruce Lyons (ed.) Cases in European Competition Policy: The Economic Analysis, (2009) Cambridge U. P.

${ }^{34}$ A further conduit was the rise of specialist economic consultancies, which grew rapidly in the late 1990s. See Damien J. Neven 'Competition economics and antitrust in Europe' Economic Policy, October 2006 pp.741-791. For a discussion on the quantification of the rise of economic effects over legal form in the EU, see Pablo Ibanez Colomo and Andriani Kalintiri, 'The Evolution of EU Antitrust Policy: 1966-2017,' 83(3), MLR (2020), 321.
} 
the consequences of an adverse determination. European legal precedent was added to a mix that would inevitably become more litigious. A key aim was that the prohibitions should encourage firms to act competitively ex ante (i.e. to enhance deterrence), rather than wait for ex post investigations.

The DGFT was charged with enforcing the new prohibitions and became the first-instance decision-maker. ${ }^{35}$ The RPC was abolished. This created a single stage of investigation with a single person determination in relation to prohibitions with high penalties, so merits appeals were legislated to provide some balance to this lack of safeguards. Appeals were to be heard by a new specialist appeals tribunal, the Competition Commission Appeals Tribunal (CCAT). The OFT retained its dual consumer and competition roles, alongside its mission "to make markets work well for consumers". ${ }^{36}$

EA02 took a formal step towards more dispersed decision making by abolishing the role of DGFT. The OFT became a corporate entity led by a CEO, Chairman and Strategic Board. Although formally made by the SoS, senior appointments were subject to a process overseen by the Commissioner for Public Appointments, including open advertisement and transparent interviewing. Stated aims for the Board were to appoint only those with expertise relevant to competition or consumer protection, and to enhance the voice of business and consumers. Consumer groups were also given a statutory role in being able to make 'super-complaints' which required a formal response from the OFT.

Nevertheless, there remained a lack of transparency in the OFT. For the prohibitions, case initiation, investigation, and decisions were all in the hands of staff. No separation was introduced between the decision to issue a Statement of Objections (SO) and the firstinstance decision. Hearings were not routine and apparently not always attended by the decision-maker. For many years, the identity of the decision-maker was not even disclosed.

EA02 distanced the SoS from merger referrals by giving the OFT a duty to refer potentially anti-competitive mergers to the CC, though the OFT could alternatively accept undertakings in lieu of a reference. The OFT was able to conduct market studies which would be the main route to using its new power to refer a market to the CC for a full investigation. ${ }^{37}$ Finally, EA02 introduced personal penalties in the form of potential incarceration under a criminal cartel offence and the disqualification of directors. This was to prove something of a poisoned chalice by greatly complicating the pursuit of cartels.

\subsection{The CC}

CA98 gave the MMC yet another new name, the Competition Commission (CC). It was to have internal separation of two panels of members from which decision groups could be selected: Reporting Members would consider merger and market references, as well as regulatory

\footnotetext{
${ }^{35}$ The sector regulators were given concurrent powers to enforce the CA98 prohibitions.

${ }^{36}$ This mission was repeated prominently at the beginning of each OFT Annual Report, including its final report for 2013-14 (HC27). Andrew Motion, then Poet Laureate and Professor of Creative Writing at UEA, once suggested to me that it would sound better if it was "to make markets work wonderfully"!

${ }^{37}$ The sector regulators were given concurrent powers to refer a market in their own sectors to the CC for investigation.
} 
appeals; and the CCAT Members would consider appeals in relation to OFT decisions. The reporting side of the CC continued to apply the public interest test and report to the SoS on mergers and monopolies. The 'monopoly' provisions of FTA73 were retained, although the prohibition of abuse of a dominant position was intended to take much of the caseload. ${ }^{38}$

EA02 returned substantive consistency in the substantive test across the institutions by replacing public interest with competition tests for mergers and market investigations. The latter replaced 'monopoly' references. The CC also became determinative on both the finding of an adverse effect and the choice of appropriate remedy - the SoS was taken out of case decision-making other than for minor public interest exceptions. The CC became accountable to Parliament through its annual review and scrutiny by select committees, and it was required to publish guidance on its approach to merger and market investigations. In its casework, it was given stronger powers to demand information and witnesses, and it was required to meet statutory timetables. It had to consult parties who might be adversely affected by its proposed decisions, which meant publishing provisional findings and a list of remedies under consideration. Its determinations were subject to judicial review by the newly-separated CAT.

The modus operandi of the CC remained very close to that of its predecessors. Each case was decided by a group of four or five members, typically including a lawyer, an economist, an accountant/finance person, and a former public sector or business executive. The group was involved early in the investigation, approving work streams, reading all the evidence submitted (apart from raw data and highly technical reports), sometimes commenting on draft staff working papers, deciding the outcome and remedies, and approving the provisional and final reports. The group attended site visits and held hearings with all main parties both early and later in the proceedings. This gave several opportunities for open discussion between the group of decision-makers and the senior management of the firms under investigation (almost always including the CEOs). The extent of involvement by the group in the details of the investigation (e.g. commenting on draft technical working papers) potentially compromised the separation of investigation and first instance determination.

All members, including the Chairman, were formally appointed by the SoS following an open process overseen by the Commissioner for Public Appointments. All were appointed for a maximum of eight years and with no possibility of renewal. EA02 brought the promise to appoint only those with expertise relevant to competition. ${ }^{39}$

\subsection{The CAT}

Whereas CA98 had created the CCAT within the CC, EA02 reinforced its independence with organisational separation as the renamed CAT. The CAT is headed by a President and there is a panel of Chairmen who are either judges or QCs. These judicial appointments are made by the Lord Chancellor on the recommendation of the Judicial Appointments Commission following an open competition. In the tradition of the RPC, either the President or a Chairman

\footnotetext{
38 The CC continued to publish around two monopoly reports each year (much the same as in the second half of the 1990s) until the new markets regime of EA02 became operational.

39 In 2004, there were 41 Reporting Members.
} 
sits with two Ordinary Members in a panel of three to adjudicate. Like the CC's Reporting Members, the Ordinary Members of the CAT are recruited in open competition according to the guidelines of the Office of the Commissioner for Public Appointments, subject to formal appointment by the SoS. ${ }^{40}$ In fact, many of the latter are former members of the CC, and they have similar attributes, including expertise in competition economics and business. Administrative support is provided by a small Competition Service, which has no capacity for further investigation.

The CAT exercises judicial review of contested decisions in relation to mergers and markets, and merits appeals in relation to the CA98 prohibitions determined by the OFT/CMA and concurrent regulators. It has additionally collected appeals roles in relation to a wide range of other regulatory decisions, including merits appeals for Ofcom's 'significant market power' decisions. Appeals in relation to fines and penalties are also adjudicated on merits. The CAT further makes first-instance decisions in relation to damages. Initially for follow-on claims, the Consumer Rights Act 2015 extended its jurisdiction to private actions and gave it power to grant injunctive relief.

CA98 appeals are conducted in an adversarial manner before the CAT. This creates a difficult switch of approach in the context of a merits appeal following an inquisitorial approach to the first-instance decision. In addition to the written evidence, there are oral hearings where witness evidence is often considered persuasive because of the ability to cross-examine. ${ }^{41}$ Decisions are quick compared to, say, appeals at the EU level. ${ }^{42}$ CAT decisions can (with permission) be appealed to the Court of Appeal.

\subsection{Performance of the OFT and CC}

In a 2010 review of the first ten years of CA98, Bloom identified a number of problems and possible causes. ${ }^{43}$ There were too few infringement decisions and they took too long. There was excessive focus in the OFT on a small number of high impact cases whereas a larger number and wider mix of cases might better promote deterrence. A high turnover of skilled staff and consequent loss of experience left the OFT vulnerable relative to stronger teams defending firms. A NAO report also emphasised problems with skilled staff retention and recruitment, especially at the level of case handlers. ${ }^{44}$ It was a highly competitive recruitment market with better remuneration offered by law firms and economic consultancies. Nevertheless, the CAT substantially upheld all the appeal decisions sufficient to warrant fines, even if those fines were mostly reduced. Two infringements without fines were successfully

\footnotetext{
${ }^{40}$ In 2019, there were 27 Ordinary Members of the CAT.

${ }^{41}$ See: Dinah Rose and Tom Richards, (2010) 'Appeal and Review in the Competition Appeal Tribunal and High Court', Judicial Review, 15:3, 201-219; Marcus Smith, 'Standards of Review and Appeal in Cases before the Competition Appeal Tribunal' (2012) 11 Competition LJ 169.

42 For example, the CAT appeal in Pfizer Phenytoin had a 13-day trial and the judgment was published 18 months after the contested decision. By way of comparison, the Intel appeal before the European General Court took five years. See Paul Gilbert 'What's the Appeal' CPI Antitrust Chronicle, Nov 2018

${ }^{43}$ Margaret Bloom is a former Director of Competition Enforcement at the OFT; Bloom, 'The Competition Act at 10 Years Old: Enforcement by the OFT and the Sector Regulators' (2010) 9 Competition L 141.

44 NAO report in 2009 HC127 Session 2008-09, https://www.nao.org.uk/wpcontent/uploads/2009/03/0809127es.pdf.
} 
appealed ${ }^{45}$ and one OFT non-infringement decision was also overturned. ${ }^{46}$ The latter resulted in an OFT preference for case closures over formal 'no grounds for action' decisions, so losing the opportunity for argued precedents.

In 2006, the OFT restructured internally from one based on legal instruments to one based on markets. ${ }^{47}$ This change may have further encouraged the use of 'easier' market studies instead of CA98 enforcement. 45 market studies were conducted by the OFT in the ten years 2003-2012, and only four infringements of the Chapter 2 prohibition in CA98. Criminalisation also delayed civil cartel cases as any criminal case had to be finalised before civil enforcement could proceed. Similarly, sector regulators preferred to use their regulatory powers instead of the prohibitions. Meanwhile, each of France, Germany and Italy were making five times more enforcement decisions than the UK, and UK decisions took significantly longer. ${ }^{48}$

The CC remained dependent on the OFT providing work. It was making an average of 15 merger decisions p.a. 2004-08, but this dropped to 6 p.a. 2008-10. With no market investigation references in 2008 or 2009, this created a serious work insufficiency problem. ${ }^{49}$ Nevertheless, one case was to have a major long-term influence on wider expectations about market investigations, and not just on the particular market under investigation. BAA had been created by privatizing ready-made state airport monopolies in London and Scotland. It had no significant rivals, and entry was impossible. It had regulated prices and demonstrably poor quality. The CC's market investigation resulted in the break-up of the airport monopolies in both regions. ${ }^{50}$ It was a successful structural intervention in a market with highly specific characteristics, but it was destined to raise expectations of structural interventions in markets with very different characteristics.

As discussed in section 2.4, case numbers are a very imperfect measure of performance, and peer reputation is a relevant qualitative indicator. The most comprehensive and widely read set of internationally comparable star ratings is published by GCR. ${ }^{51}$ The maximum rating is $5^{*}$. Figure 1 shows that the OFT averaged $41_{4}^{*}$ over the period $2006-13$. The CC achieved the

\footnotetext{
45 The Racecourse Association and Others v Office of Fair Trading; The British Horseracing Board v Office of Fair Trading, (Case Nos 1035/1/1/04 and 1041/2/1/04) [2005] CAT 29, [2006] CompAR 99. MasterCard UK Members Forum Ltd and Others v Office of Fair Trading Supported by The British Retail Consortium, (Case Nos 1054/1/1/05, 1055/1/1/05, 1056/1/1/05) [2006] CAT 14, [2006] CompAR 595.

${ }^{46}$ ME Burgess, JJ Burgess and SJ Burgess (trading as JJ Burgess \& Sons) v Office of Fair Trading and W Austin \& Sons, Harwood Park Crematorium Ltd, The Consumers' Association, Case No 1044/2/1/04) [2005] CAT 25, [2005] CompAR 1151. A further CA98 decision by Ofwat was also overturned: (Case Nos 1046/2/4/04, 1034/2/4/04(IR)) [2006] CAT 36, [2007] CompAR 328; and Albion Water Ltd v D\&r Cymru Cyfyngedig (Water Services Regulation Authority intervening) [2008] EWCA Civ 536, [2009] 2 All ER 279.

47 DG Competition had made a similar change in 2004.

${ }^{48}$ See the formal consultation that preceded ERRA13: BIS (n10).

${ }^{49}$ Merger references partially recovered to 11 p.a. 2011-13, and the flow of markets references returned to normal. See section 5.2 for judicial review of markets cases.

50 'BAA airports market investigation' (2009) available at:

https://webarchive.nationalarchives.gov.uk/20140402170709/http://www.competitioncommission.org.uk/our-work/directory-of-all-inquiries/baa-airports/final-report-and-appendices-glossary

${ }^{51}$ Global Competition Review, Rating Enforcement, (various years), available at https://globalcompetitionreview.com/edition/1001376/rating-enforcement-2019.
} 
maximum $5^{*}$ alongside the highest rated US agencies and DG Competition, only dropping to $41^{*}$ in the year before its abolition as an independent agency.

Figure 1: International Reputation of OFT, CC and CMA

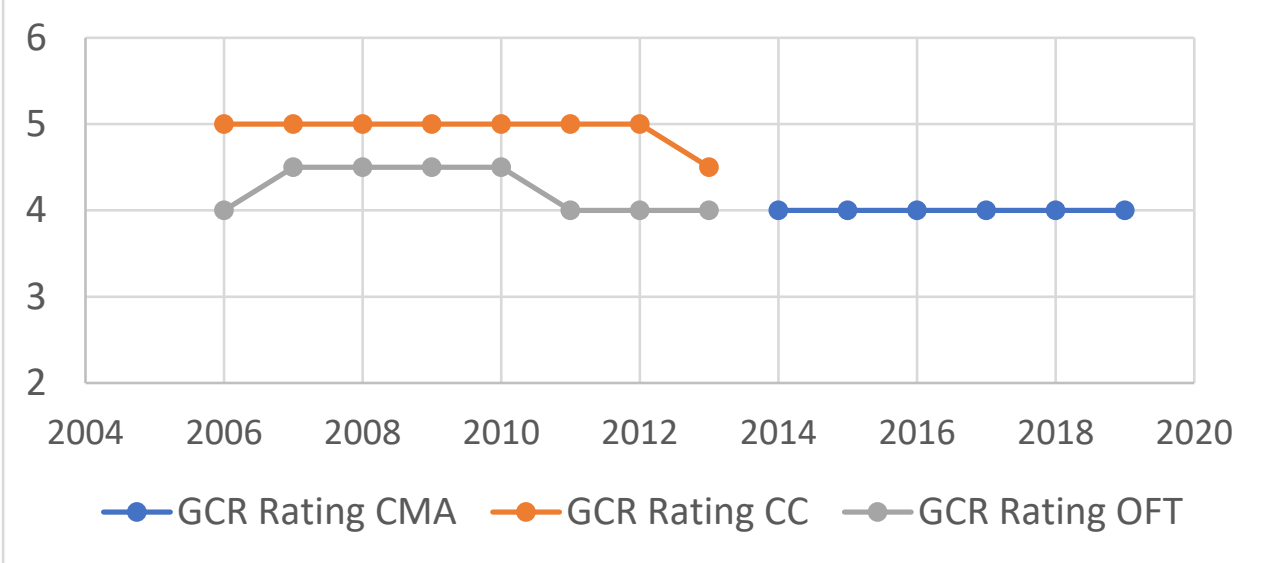

\section{Compromise(d) merger: ERRA13 and the CMA}

The government set out three objectives in motivating its 2011 consultation on further reforms: to improve the robustness of decisions and strengthen the regime; to support the competition authorities in taking forward high impact cases; and, to improve speed and predictability for business. ${ }^{52}$ With these objectives in mind, ERRA13 brought about the most substantial organisational change since the creation of the OFT. The OFT and CC were merged to form the Competition and Markets Authority (CMA).

There were also significant strengthening of the merged organisation's powers and measures to speed up investigations. These included: a range of enhancements to investigation powers and interim measures for CA98 investigations; sector regulators were required to consider the use of their concurrency powers before using their licence enforcement powers, with the CMA being given a leadership role in promoting this; ${ }^{53}$ statutory time limits were introduced for the mergers and the markets regimes; a change to the criminal cartel offence; and, there was a new power for the SoS to request the CMA to investigate a specified public interest issue in a market investigation. ${ }^{54}$

\footnotetext{
52 BIS (n 10).

${ }^{53}$ ERRA13 gives the CMA a coordinating role in CA98 concurrency, including the ability to decide whether a sector regulator or the CMA should lead on an enforcement case. The UK Competition Network (UKCN) provides the forum for strategic dialogue, promotion of enforcement cooperation and capabilities, advocacy and case activity. United Kingdom Competition Network (UKCN) Statement of Intent

https://www.gov.uk/government/publications/uk-competition-network-statement-of-intent . CROSS REF BY EDITORS REQUIRED

${ }^{54}$ Most of these are discussed in depth in other chapters of this book.
} 


\subsection{CMA design}

\subsubsection{Mandate}

The CMA was given a primary duty "to promote competition, both within and outside the United Kingdom, for the benefit of consumers". ${ }^{55}$ This was developed by the Board to set out a new mission: "The CMA makes markets work well in the interests of consumers, businesses and the economy." 56 This appeared to presage a wider focus than the old OFT mission only "to make markets work well for consumers", but there is little evidence of any wider emphasis on "businesses and the economy".

The CMA is constituted as a Non-Ministerial Department, much like its predecessors and has independence to prioritise its own activities and use of resources. It is directly accountable to the Public Accounts Committee, and is set the Treasury target to achieve $£ 10$ of measured consumer benefits for every $f 1$ of its costs. The CMA's strategic direction is set by a Board consisting of a Chairman, CEO and other senior CMA executives, and non-executive directors formally appointed by the SoS. The appointments process is overseen by the Commissioner for Public Appointments. Board members are appointed for fixed terms but can be reappointed without limit. ${ }^{57}$

The Board determines resource allocation and decision processes. The SoS feeds into this by issuing a non-binding Ministerial Strategic Steer outlining the Government's strategic priorities for the CMA. ${ }^{58}$. While this may look like overtly political interference, it is probably better interpreted as providing transparency in the inevitable line of communication between government and an important public body. It would be more worrying if private discussions were influential in case selection and determinations. The first Chairman of the CMA, David Currie, was a highly experienced regulatory economist. The second, Andrew Tyrie, had an early career as an economist, then spent twenty years as an influential backbench MP prior to his appointment. It is difficult for an outsider to know the extent to which this political background affected the relationship between the CMA and SoS.

The range of consumer responsibilities previously held by the OFT was reduced (e.g. credit licensing and anti-money laundering was transferred to the FCA, and Local Trading Standards Services became the [under-funded] lead enforcers of consumer protection legislation), but the CMA retains a leadership role in issuing guidance and taking on key consumer cases. ${ }^{59}$ Thus, the CMA was designed to focus more clearly on competition law, but it retains the link with consumer law. This is helpful given the growing awareness that consumers do not always

\footnotetext{
55 ERRA13, s25(3).

${ }^{56}$ See CMA13 'Vision, values and strategy for the CMA' January 2014. This mission is repeated prominently alongside its primary duty at the front of every CMA annual report.

${ }^{57}$ This contrasts with appointments in line of descent from the CC (including the CMA panel members and Panel Chair), which are non-renewable.

${ }^{58}$ For the most recent steer, see BEIS, The Government's Strategic Steer to the Competition and Markets Authority, July 2019.

59 The sector regulators also have consumer enforcement powers. Citizens Advice provides consumer advocacy, education and advice.
} 
act with classic rationality and effective competition policy needs to take account of 'behavioural' consumers.

\subsubsection{Organisational design and decision-making}

The Board decides on opening market studies and references for full market investigation. Other case decisions are made in ways inherited from the OFT and CC, and this has determined the internal structure of the CMA. It is split into two delivery directorates whose executive directors sit on the Board. The enforcement directorate continues the OFT mandate on cartels, CA98 prohibitions, and consumer protection, with each section headed by a senior director. The markets and mergers directorate brings together the OFT's first phase role and the CC's second phase role, with separate senior directors for markets and mergers. Most staff working on cases and projects work flexibly across directorates. There is also a separate General Counsel with legal service, and a Chief Economic Adviser with separate office. Both attend Board meetings in a non-voting capacity. Carrying over from the CC's Reporting Members, there is a CMA Panel including a Panel Chair. Two Panel Members, normally including the Panel Chair, sit as non-execs on the Board.

Decision-making in each CMA directorate follows different processes inherited from the OFT and CC. For CA98 cases, the OFT had made a belated move to replace individual decisionmakers with Case Decision Groups (CDGs) and appointed a Procedural Officer. Both were put on a statutory footing by ERRA13. Other changes were improved transparency in identifying decision-makers and greater internal challenge at key stages of case development.

Following intelligence about a possible competition issue (e.g. whistle-blowing or a complaint) and the application of prioritisation principles, a case may be passed to the enforcement directorate. CA98 cases are then developed in two stages with the same investigation team but separate decision-makers. ${ }^{60}$ If a case is opened, a case team is allocated to direct the investigation and a Senior Responsible Officer (SRO) is nominated to oversee and decide provisionally whether there has been an infringement. If so, a Statement of Objections (SO) is issued and, if the parties do not accept the infringement and reach a settlement, a 3-person CDG is appointed to oversee the second phase, attend any oral hearing and make the final determination. The SRO cannot be a member of the CDG but continues to work with the case team. The CDG may be entirely CMA staff, or include one or possibly two panel members. ${ }^{61}$ The CMA's lack of a fully independent decision group stands in contrast to the leading concurrent regulators. Ofgem and the FCA both have fully independent expert panels to determine CA98 cases presented by internal staff. ${ }^{62}$

CMA CDGs are appointed by the Case and Policy Committee (CPC). This consists of eight CMA executives plus two Panel Members (more specifically, inquiry chairs). It is chaired by the CEO

\footnotetext{
60 'Competition Act 1998: Guidance on the CMA's Investigation Procedures in Competition Act 1998 Cases', 18 January 2019, CMA8.

${ }^{61}$ The published decision on Phenytoin Case CE/9742-13 reveals that there were only two members of the CDG; one was a Panel Chair and the other a staff Economics Director.

62 For Ofgem's Enforcement Decision Panel, see 'Ofgem Enforcement Guidelines' (2017). The CAA also uses the Ofgem EDP. For the FCA's Competition Decisions Committee, see 'Corporate Governance of the Financial Conduct Authority' March 2020.
} 
and accountable to the Board. Its terms of reference include "advising teams on legal, economic or policy issues arising from individual cases and projects... promoting consistency of the CMA approach and application of policy across all cases, projects and tools." In addition to appointing CDGs to determine CA98 investigations (including infringement, no grounds for action and penalty decisions), it considers the proposed decisions of a CDG, and provides advice and recommendations on any policy, legal or economic issues the CDG should consider further before finalising its decision. It further approves decisions of senior staff on the use of commitments or settlements in CA98 investigations.

This suggests that the CPC is highly influential in individual cases. Its membership is dominated by the top of the executive hierarchy and in direct line of management of any staff appointment to a CDG. The careers of staff members on a CDG thus depend on the CPC. Furthermore, they may be dependent on the SRO who wrote the SO. A further distortion is that the CDC chooses the legal instrument used to address a suspected competition issue (e.g. consumer enforcement or antitrust enforcement or, on approval by the Board, market study), and in doing so it may be influenced by the greater independence of decision-making by a group determining a market investigation.

Case development and decision making in the mergers and markets directorate largely carries over from the CC. The two phases of decision-making in merger and market investigations are retained, with the first phase being conducted by staff and the second phase being conducted by independent groups chosen from Panel Members. Referral for a phase 2 market investigation is made by the Board, while merger referrals are by a single decisionmaker. A significant difference brought about by the CMA is the continuity of investigation staff across phases 1 and 2, which can be efficient but it reinforces the importance of independent decision groups. Groups require a two-thirds majority for adverse findings. Panel Members continue to adjudicate on regulatory appeals. The role of CC Chairman is reduced to that of Panel Chair who selects each case group from the Panel Members.

In short, there was little design in the creation of the CMA - the OFT and CC were simply squeezed together. Of course, this was a low risk consensus adaptation in the short run, and it provided a non-disruptive transitional arrangement, but it is not a coherent institutional design. ${ }^{63}$ The CMA's proposals for reform (discussed below) suggest a desire to move closer to the OFT's executive institutional culture. ${ }^{64}$

\subsection{CMA Performance}

On its formation, the CMA was granted an additional $f 12 \mathrm{~m}$ to expand its competition work, but it was again beset by staffing problems. Prior to the merger, the OFT had around 650 staff, of which around 150 were in credit licensing and anti-money laundering. The CC

\footnotetext{
63 In 1996, Sir Gordon Borrie had already expressed concerns: "I am not too keen on joining the OFT and MMC together because they have different cultures and the more questioning, partisan, activities of the OFT are not naturally combined with the necessarily more cautious, impartial and judicious approach of the MMC. Yes, you can combine in one body the roles of investigator, prosecutor and judge, but justice does need to be seen to be done." Quoted by Wilks (n 19) 322.

${ }^{64}$ As of mid-2020, none of the eleven Board members was previously associated with the CC. The Panel Chair and additional non-exec Panel Member were both first appointed to the Panel only in September 2018.
} 
employed around 160. The CMA employed 653 at the end of 2014 and a similar number over the next four years. However, that simple arithmetic misses the staff turnover and loss of morale during the transition. The OFT's permanent workforce dropped to 477 and the temporary workforce rose to nearly 200 in the year prior to the merger. Staff recruitment and retention was made particularly difficult by the simultaneous expansion of competition units in sector regulators. In the two years 2013-14, nearly forty staff left the OFT/CC/CMA for a sector regulator, half to the FCA which offered higher salaries, and the rest spread across seven other regulators. Experienced senior staff were a particular loss. ${ }^{65}$

There has been a modest increase in the number of CA98 decisions. The OFT averaged only two infringement findings p.a., with 12 in the five-year period 2000-04, 10 in 2005-09, and 10 in 2010-14. ${ }^{66}$ Sector regulators chipped in with a couple more over the 15 years but more often they found no grounds for action. There was a step change 2015-19, with the CMA finding five and six infringements in 2016 and 2017, although it averaged only two p.a. for the other three years, and the regulators chipped in with an average one p.a. between them. In addition, the CMA and regulators have reached five settlements. Overall, the number of infringement or settlement findings by the CMA and concurrent regulators has risen from two p.a. to an average of five p.a.. The time taken to complete CA98 investigations has also been halved. ${ }^{67}$

This is a positive achievement, but it remains an internationally small number of enforcement cases, which has consequences. It severely limits precedent, which is important both for firms (clarification, guidance and deterrence), and for the CMA itself (experience, identification of pitfalls and methodology). The latter is highlighted by the fact that the CMA has found only one Ch.2 excessive pricing infringement, and on appeal the CAT remitted the case due to the CMA's incomplete analysis of the excessiveness of price (Phenytoin). ${ }^{68}$ Unwisely, the CMA took the CAT's judgment to the Court of Appeal and substantially lost, which delayed the opening of the remittal by a full two years. ${ }^{69}$ The only other Ch.2 (also Ch.1) infringement finding by the CMA was for exclusionary conduct (Paroxetine), which was also appealed. ${ }^{70}$

\footnotetext{
65 Source: OFT, CC and CC annual report and accounts.

${ }^{66}$ Source: author's count of cases from the CMA cases website https://www.gov.uk/cmacases?case type $\% 5 \mathrm{~B} \% 5 \mathrm{D}=$ ca98-and-civil-cartels\&case state\%5B\%5D=open and (for pre-2010) Bloom (n 45). These exclude private actions. For simplicity, I refer to calendar years when the data refers to financial years finishing the following April. For greater detail, see Barry J. Rodger, 'Application of the domestic and EU antitrust prohibitions: an analysis of the UK competition authority's enforcement practice', [2020] 8 Journal of Antitrust Enforcement, 86-123.

${ }^{67}$ BEIS 'Competition Law Review: post implementation review of statutory changes in ERRA13' April 2019

68 Unfair pricing in respect of the supply of phenytoin sodium capsules in the UK, Case CE/9742-13 [2016]. Flynn Pharma Ltd and Flynn Pharma (Holdings) Ltd v Competition and Markets Authority; with Pfizer Inc. and Pfizer Limited $v$ Competition and Markets Authority (Phenytoin) [2018] CAT 117

${ }^{69}$ Case No: C3/2018/1847 \& 1874 [2020] EWCA Civ 339. The author had no role in this case but the gap in the CMA's reasoning (reliance on margins to the exclusion of a natural comparison of the price of capsules and tablets) was clear even before the non-confidential decision was published, let alone the CAT judgment. See blog by Farasat Bokhari and Bruce Lyons at https://competitionpolicy.wordpress.com/2016/12/16/pfizer-andflynn-how-are-excessive-prices-for-generic-drugs-possible-and-should-competition-authorities-do-moreabout-exploitative-pricing/.

${ }^{70}$ Paroxetine - Case CE-9531/11 [2016].
} 
The CAT's judgment on that case has been delayed due to questions being referred to the CJEU. The CMA has been more successful with Ch.1 appeals, other than in the level of fines. ${ }^{71}$

For mergers, there was a higher propensity to accept undertakings in lieu of a reference than in the ten years before the CMA. If we define merger interventions as either phase 1 undertakings in lieu of a reference or referral for phase 2, the share of phase 1 settlements rose from $32 \%$ pre-CMA to $43 \%$ in 2014-19. This is consistent with reaching outcomes more quickly. There has been no discernible impact on the number and distribution of phase 2 outcomes. In terms of workload, and given that the CMA has no control over merger activity, the flow of qualifying mergers for consideration has also been remarkably steady at around sixty or seventy p.a.. The time taken for both merger review and the markets regime have been reduced, which owes more to statutory time limits than to the creation of the CMA per se.

For markets, phase 1 activity had been around 4 p.a. at the OFT, but this has fallen to 2 p.a. under the CMA. ${ }^{72}$ The CMA inherited five open phase 2 cases from the $\mathrm{CC}$, including one remittal, but it has only opened four phase 2 investigations in six years itself. Two of those (domestic energy and retail banking) followed phase 1 collaboration between the OFT and sector regulators, and another (investment consultants) was referred by the FCA in 2017. The funerals market reference in 2019 is the only phase 2 market investigation generated entirely under the CMA's own initiative.

The energy and banking investigations were opened almost simultaneously in the first few months of the CMA in 2014. This was a substantial and possibly damaging workload for the new organisation. Earlier that year, the CC/CMA had published two final reports each of which included structural remedies (divestitures). The structural remedy proposals in one (private healthcare) did not survive an appeal with remittal, ${ }^{73}$ and potential appeal of the other (aggregates) was overtaken by negotiations to push a much bigger Europe-wide merger through the European Commission in Phase $1 .{ }^{74}$ No new markets work was opened in 2015, and of the eight market studies opened from the start of 2016 to mid-2020, only one (funerals) led to a phase 2 market investigation. ${ }^{75}$ There appears to be impatience with fullyevidenced investigations by independent groups of Panel Members, who have typically chosen behavioural remedies over structural remedies, usually for the very good reason that

\footnotetext{
${ }^{71}$ E.g. Ping Europe Limited v Competition and Markets Authority [2018] CAT 13.

${ }^{72}$ Own calculations based on CMA website https://www.gov.uk/cma-cases?case type\%5B\%5D=markets

73 'Private healthcare market investigation: Final report' 2 April 2014, CC; 'HCA International Limited v Competition and Markets Authority' CAT Case 1228/6/12/14, in which the CMA accepted its mistakes in data analysis, and the CAT quashed both the finding of an adverse effect of competition in Central London and the divestiture remedy. The CMA's Remittal final report, without any divestiture remedy, was published 17 months after its original final report.

74 'Aggregates, cement and ready-mix concrete market investigation: Final report' 14 January 2014, CC. For the European merger, see European Commission case M.7252 Holcim/Lafarge, 15 December 2014.

75 In addition, there was one response to a super-complaint (on the loyalty penalty). The flow of market investigations from the regulators is likely influenced by a preference for the use of regulatory powers. To complete the picture of caseload, the average number of consumer enforcement cases per annum remained essentially unchanged compared with the OFT at around 25 p.a.. CROSS REFERENCE EDITORS
} 
the identified competition failures were due to features of the market other than the number of firms. ${ }^{76}$

The CMA's 10:1 consumer benefits to costs target set by $\mathrm{H}$ M Treasury has not been helpful. If the target means anything, failure to meet it would result in substantial budget cuts and the debilitating loss of skilled staff. This creates insidious distortions. It is difficult to measure the value of deterrence or precedent, so has created undue pressure for large scale market investigations arguably at the expense of more socially beneficial case choice. It shifts focus away from cartels (which are typically in small markets) and the abuse of dominance (which is typically an exclusionary abuse without immediate price effects), and may help explain why the CMA conducts so few enforcement cases. ${ }^{77}$ Beyond case selection, the target adds pressure on CMA staff for adverse findings and promotes measurable interventions.

The CMA has an important advocacy role in promoting competition between firms. In 2018, it commissioned a survey of 1,200 UK businesses to test how its message was getting across. Only $3 \%$ of respondents could name the CMA as the official body responsible for enforcing competition law in the UK. ${ }^{78}$ When prompted with a list of possible answers, $49 \%$ said the OFT, $15 \%$ said the CC and $14 \%$ said the CMA. This suggests more could be done in raising business awareness. It further suggests that there is a danger in confusing businesses, let alone consumers, with too many institutional name changes.

Finally, the CMA's international reputation is very good, but it is some way from being world leading. As Figure 1 shows, the CMA inherited the OFT's $4^{*}$ rating and has been stuck at $4^{*}$ ever since. In 2019, France, Germany and the US FTC were given the elite $5^{*}$ rating. Australia, European Commission, Japan, South Korea and the US DOJ were $4 \frac{1}{2}{ }^{*}$, and Brazil was alongside the CMA on $4^{*}$.

\section{The case for institutional reform}

\subsection{Five new 21st century challenges}

Five very substantial new challenges add further pressure for CMA reform.

\subsubsection{Loss of public faith in markets}

There has been a public and political loss of faith in markets to deliver the best outcome for consumers. ${ }^{79}$ At the turn of the millennium, there was a strong political consensus on the benefits of competition. Competitive markets would provide consumers with what they

\footnotetext{
${ }^{76}$ As noted in section 4.5, the BAA case was a monopoly structure, which is rare to find in market investigations. See section 6.2.2 for an expression of this impatience.

77 The CMA's own estimated average annual consumer savings relative to costs (2017-20) show that competition enforcement (CA98 outcomes) covered just under $50 \%$ of costs, whereas market studies and market investigations alone covered over nine times costs; CMA Impact Assessment, 14 July 2020, CMA121.

78 'Competition law research 2018' a report by ICM on behalf of the Competition and Markets Authority; available at https://www.gov.uk/government/publications/uk-businesses-understanding-of-competition-law. ${ }^{79}$ For example: James Kirkup, Better Regulators, Fairer Markets, 2019, Social Market Foundation; Maurice E. Stucke and Ariel Ezrachi, Competition Overdose: How Free Market Mythology Transformed Us from Citizen Kings to Market Servants, 2020, Harper Collins.
} 
wanted at the lowest feasible price, and provide the right incentive for innovation and productivity growth. The consensus went further to agree that the promotion of competition was a technical matter best left to experts. Politicians could then focus on wider policy. The 2008 banking crisis and bailouts, and the subsequent years of austerity and recession, shook faith in capitalism and failures in financial markets have affected faith in product markets. ${ }^{80}$ A particular concern has been the unfairness of some pricing practices, especially those disproportionately affecting 'vulnerable' consumers. There has further been an international rise in economic nationalism, leading to pressures for public interest interventions. This makes the CMA's role in enforcement and advocacy both harder and more important.

\subsubsection{Digital markets and dominant platforms}

The digital economy, especially the dominant digital platforms, create a major challenge. Digital markets have many characteristics that are also found in more traditional market settings (e.g. network effects, cross-network externalities, continuous marginal innovation, drastic Schumpeterian innovation, high fixed/low marginal costs, global reach, big data accumulation, targeted advertising, potential for price discrimination). However, there is a major qualitative difference in that so many of these characteristics are combined in digital settings and their effects are exacerbated by personalised data. Furthermore, digital technology can be used globally without transport costs, marginal costs are often close to zero, and a very small number of platforms have become both first-choice access points for time-constrained consumers and the core route-to-market for many suppliers. The result has been dominant digital platforms, even at the global level.

The CMA has been taking measures to address the digital challenge. Its mandate in consumer law is important for tackling issues that might otherwise fall in a gap between competition and consumer laws. Provoked by the independent Furman inquiry on digital competition, it conducted a market study into online platforms and digital advertising. It leads a Digital Markets Taskforce operating jointly with the Information Commissioner's Office and Ofcom. At the time of writing, it seems likely that a permanent Digital Markets Unit will be established by the government to regulate digital businesses designated as having 'strategic market status', but it is not clear whether this would be located within the CMA or Ofcom or as a separate organisation. The CMA has made clear that it wants new powers and has adopted a new slogan that the 'UK has an analogue system of competition and consumer law in a digital age' $^{81}$

\subsubsection{Brexit including scrutiny of state subsidies}

Brexit brings a step change in the CMA's workload as it takes on international mergers and antitrust cases previously dealt with in Brussels. DG Competition has averaged 95 'significant' mergers p.a. since 2014, where 'significant' is defined for this purpose as requiring a Phase 1 investigation that does not qualify for the simplified procedure. If only a third of these have an impact on the UK market, this would be a 50\% increase in the CMA's caseload and include

\footnotetext{
${ }^{80}$ For example, Maurice E. Stucke, 'Reconsidering Antitrust's Goals', 53 B.C.L. Rev.551 (2012), http://lawdigitalcommons.bc.edu/bclr/vol53/iss2/4.

${ }^{81}$ Chairman and CEO Foreword to the Annual Plan 2020/21. CROSS REFERENCE EDITORS TO CH 14
} 
mergers of a much greater scale and complexity than domestic mergers, so effective workload will be higher still. ${ }^{82}$

The required increase in CA98 cases is of an even greater magnitude. How well placed is the CMA to take on an abuse of dominance case against any of the online platform giants? The CMA has published just two Ch.2 decisions since its formation six years ago, both in 2016, both for pharmaceuticals, and both found wanting in the CAT. Meanwhile, the European Commission undertook sixty Art.102 investigations, including 27 decisions in the same period. These include cases against US giants Intel, Google, Amazon and Qualcomm, which would be in the CMA's remit post-Brexit. Tools go rusty if unused, so there must be a question mark against the CMA's experience and ability to challenge potential abuse by internationally dominant firms. The loss of cooperation and information sharing within the European Competition Network ('ECN') is an additional problem, particularly with confidential information in Ch.1 cases, as it will be a major impediment to investigations involving precisely the international firms and cartels investigated by DG Competition.

The CMA's enforcement directorate has been given the additional task of investigating state aid (i.e. subsidies that may distort competition). At the time of writing (June 2020), this remains a highly contentious issue and the CMA's role will remain unclear until a trade deal (if any) is agreed with the EU. Prior to the Covid emergency, the EC investigated around 500 state aid cases p.a., with only 25 of those relating to UK subsidies. Political opinion on both left and right is becoming more interventionist, so contentious spending is likely to rise. Additionally, 'repatriated' EU spending broadens the potential for granting aid (e.g. agriculture, regional, infrastructure). Devolution of spending decisions within the UK raises politically sensitive issues of intra-UK monitoring and review (e.g. Scotland, Wales, Northern Ireland, English cities/regions). State aid is the most political and time-consuming activity in DG Competition. ${ }^{83}$ Even if the workload will be relatively lower for the CMA, it has the potential to be even more contentious as it does not benefit from the distance between Brussels and most Member States.

The government's allowance for all Brexit-related issues has been a $£ 20 \mathrm{~m}$ p.a. increase the CMA's budget to around $190 \mathrm{~m}$. The CMA expanded its staffing from 640 at the end of March 2018 to 853 a year later, making it larger than DG Competition. At least in part in preparation

\footnotetext{
82 The $50 \%$ increase is identical to the CMA's own estimate in its Annual Plan for 2020/21. It may turn out to be an underestimate given recent CMA interpretation of its jurisdiction. For example, in 2020 the CMA prohibited the merger of two US airline booking software firms whose UK sales were to a single airline, BA. 'Anticipated acquisition by Sabre Corporation of Farelogix Inc.: Final report' 9 April 2020. Meanwhile, the European Commission is becoming more active in monitoring foreign ownership of strategic assets and there are proposals to extend merger review to appraise the distortionary effects of acquisitions by foreign state-owned or state-subsidised firms: https://trade.ec.europa.eu/doclib/docs/2020/march/tradoc 158676.pdf; https://ec.europa.eu/competition/international/overview/foreign subsidies white paper.pdf. If the UK follows suit, that would be additional work for the CMA.

${ }^{83}$ On a simple count of case decisions during the decade 2010-19, the Commission made 123 antitrust/cartel decisions, 3,401 merger decisions and 4,281 state aid decisions. Although this case count is unweighted by case complexity, state aid cases are rarely straightforward and the number count excludes both the height of the financial crisis and the Covid-19 emergency measures.
} 
for its new state aid role, the CMA has established regional offices in Edinburgh, Belfast and Cardiff.

\subsubsection{Covid-19 pandemic}

The Covid-19 pandemic has had profound effects on markets. Both demand and supply have been subject to major shocks, with resulting price swings, some of which are the natural operation of competition. In the longer term, supply adjustments leading to exit may raise concentration and market power. Some of the biggest winners of the Covid-19 induced change in consumption patterns are the global digital platforms, reinforcing digital market concerns.

The CMA has established a Covid-19 taskforce to monitor issues. Price rises trigger public scrutiny even if they are the natural result of forces of supply and demand, so careful advocacy is necessary to control expectations and highlight what can and what should not be done. ${ }^{84}$ Much of the CMA's Covid response has been using consumer law (e.g. for refunds), but it did launch four investigations related to suspected charging of excessive and unfair prices for hand sanitiser products under Chapter 2 of CA98. ${ }^{85}$ Within a month, it had dropped all four cases.

The government has introduced some measures that have the effect of suppressing enforcement. Merger legislation has been amended to add a new public interest of maintaining capability to combat a public health emergency. This may be pro-competitive if it prevents opportunistic bids for, say, a vaccine supplier, but it could be the opposite if used to support a bid to create a national champion. ${ }^{86}$ Crisis cooperation agreements may have a short-term role but they forge connections between firms that will be hard to let go after the immediate crisis. ${ }^{87}$ The failing firm defence in mergers is likely to be tested but it will be hard to assess. ${ }^{88}$

\footnotetext{
${ }^{84}$ The Financial Times (17 May 2020) reported that the CMA has asked BEIS for "emergency time-limited legislation" to prevent 'price gouging'. This was in response to a spike of consumer complaints about products with suddenly increased demand, including hand sanitisers. Shortly afterwards (21 May 2020), a CMA Covid Taskforce update revealed that the spike in price complaints in late March and early April had dropped to a negligible level by May, with the overwhelming number of complaints now relating to holiday and flight refunds.

${ }^{85}$ Hand Sanitiser Products: Suspected Excessive and Unfair Pricing, Case reference: 50924. It separately reported that hand sanitiser was the worst case of suspected 'price gouging' with the median reported complaint to the CMA being for a $400 \%$ price increase: Update on the work of the CMA's Taskforce, Published 3 July 2020; https://www.gov.uk/government/publications/cma-coronavirus-taskforce-update-3-july2020/update-on-the-work-of-the-cmas-taskforce

${ }^{86}$ Urgent exceptions, like Lloyds/HBOS during the banking crisis, can be forced through in haste then regretted at leisure; Bruce Lyons \& Minyan Zhu, Compensating Competitors or Restoring Competition? EU Regulation of State Aid for Banks During the Financial Crisis, 2012, Journal of Industry, Competition and Trade.

${ }^{87}$ For example, the SoS signed The Competition Act 1998 (Dairy Produce) (Coronavirus) (Public Policy Exclusion) Order 2020. The CMA's position is set out in CMA Approach to Business Cooperation in Response to COVID-19, 25 March 2020, CMA118. For an international perspective, see OECD, Co-operation between competitors in the time of COVID-19, 26 May 2020.

${ }^{88}$ The difficulties are illustrated by Amazon/Deliveroo where the failing firm defence was first accepted by the CMA, then rejected, but the merger was still allowed; https://www.gov.uk/cma-cases/amazon-deliveroomerger-inquiry.
} 


\subsubsection{Climate change}

Climate change has finally reached prominence in the national policy agenda. The CMA's 2019/20 annual plan listed four strategic priorities: protecting vulnerable consumers; improving trust in markets; digital competition; and economic growth and productivity. For the first time "supporting the transition to a low carbon economy" was added to the list in the 2020/21 plan. The CMA proposes very cautious first steps to develop an understanding of how climate change goals affect markets, and action to protect consumers from misleading 'green' claims. However, the CMA is likely to have to adapt further, possibly to include an evaluation of climate externalities as part of the competition analysis where this is likely to be relevant. Examples might include a merger that would eliminate high carbon production but reduce capacity, or a research agreement between horizontal rivals to develop a green technology. In post-Brexit state aid control, it should be relatively straightforward to accommodate aid to reduce carbon emissions but it would be politically highly controversial actively to penalise aid for carbon intensive sectors (e.g. airlines). ${ }^{89}$

\subsection{CMA's own proposals for reform: the Tyrie letter ${ }^{90}$}

In early 2019, Chairman of the CMA Andrew Tyrie sent a letter to the then SoS Greg Clark requesting new powers to allow it to act quickly and with reduced oversight by the CAT. ${ }^{91}$ Two motivations were given: "First, the growth of new and rapidly-emerging forms of consumer detriment, caused in part by the increasing digitalisation of the economy, requires more rapid intervention, and probably new types of intervention... Second, there are increasing signs that the public doubt whether markets work for their benefit."

The Tyrie letter makes eight proposals, but three get to the heart of the CMA as an institution: i) "consumer interest" to replace competition as the CMA's "overriding statutory duty"; ii) new powers to impose legally binding interim remedies during a phase 1 market study, which would also "enable the CMA more effectively to influence the conduct of those businesses whose practices raise concerns, without the need for formal work in the form of market studies or market investigations."; and, iii) a more limited standard of review for CA98 cases.

\subsubsection{The consumer interest as an overriding statutory duty}

\footnotetext{
${ }^{89}$ See also Simon Holmes, 'Climate Change, Sustainability, and Competition Law', (2020) 8 Journal of Antitrust Enforcement, 354-405, for an EU perspective; and for a UK perspective, his blog on Climate Change, Sustainability and Competition Law: Lessons From Covid 19, 23 April, 2020, , http://competitionlawblog.kluwercompetitionlaw.com/2020/04/23/climate-change-sustainability-andcompetition-law-lessons-from-covid-19/?doing wp cron=1596110215.9190039634704589843750. ${ }^{90}$ Since this chapter was drafted, Lord Tyrie has announced his resignation as Chairman of the CMA as from September 2020 (i.e. after only three years in post). Tyrie was the sole signatory of the letter to the SoS. Nevertheless, his letter says: "The proposals are the product of careful consideration by senior CMA staff, and discussion at Executive and Board level" so it must be presumed that the letter remains CMA policy. This section draws on the author's CCP blog published 07/03/2019

https://competitionpolicy.wordpress.com/2019/03/07/why-the-cma-is-wrong-in-its-proposals-for-reformand-what-should-be-done-instead/

91 https://www.gov.uk/government/publications/letter-from-andrew-tyrie-to-the-secretary-of-state-forbusiness-energy-and-industrial-strategy $21^{\text {st }}$ February 2019,
} 
The OFT's mission to "make markets work well for consumers" captured both the fundamental importance of competitive markets and the regulator's focus on who markets should benefit. The regulator's job was to ensure that consumers have a competitive range of opportunities to choose from, and then leave them to make their own choices. Cutting out the role of markets/ competition and fast-tracking to "the consumer interest" risks a wideranging and paternalistic determination of what is the consumer interest. This echoes the language and problems of previous "public interest" tests. There is a worrying absence of any discussion in the Tyrie letter of how the consumer interest will be determined. What exactly is the consumer interest other than in relation to what the market provides and consumers choose? The great concern is that consumer interest becomes whatever the CMA deems it to be. ${ }^{92}$

Nevertheless, it remains problematic that the CMA's primary duty in ERRA13 is to promote competition for the benefit of consumers, and this exclusive role of supply-side competition underplays the CMA's role in consumer law. Markets may be distorted on the demand-side if consumers are, for example, uninformed or misled despite (or even because of) fierce competition.

\subsubsection{Anticipated use of interim measures in the markets regime}

Phase 2 market investigations provide the CMA with uniquely strong powers to intervene in markets where firms are not suspected of illegal practices. Market investigations have been used recently to promote competition through demand-side remedies which help consumers become better informed and better able to switch suppliers (e.g. energy, retail banking). It is reasonable to observe that the markets regime can be a lengthy process and that interim measures would be helpful in fast moving markets. However, in line with the proposed change is statutory duty, the letter proposes to extend the powers of a market investigation to include either competition or the interests of consumers.

The aim seems to be to incentivise firms to cooperate before a market study has to be opened, and the arbiter of consumer interest will tell them what to do. Tyrie writes:

"Weighing on the minds of management in deciding whether to cooperate with the CMA would be the alternative: direct intervention, in the form of legally-binding requirements. ... Many of these exchanges would occur in private. Early public communication of problems in markets, and sources of consumer detriment, could also encourage improvements to behaviour. .... Legal protections may also be required to ensure that the CMA is adequately protected from defamation liability..." [pp.17-18].

This reveals an impatience with formal market investigations and the loss of executive control once independent panels have been appointed. A Consumer Interest Authority, possibly guided by focus groups, media or political opinion, could decide which firms and in which markets pricing and other business strategies should be controlled - without the necessity for

\footnotetext{
92 The proposal also looks odd in the context of the CMA's own revised mission to make markets work well in the interests of consumers, businesses and the economy. See section 5.1.1.
} 
either an investigation or an objective definition of consumer interest. ${ }^{93}$ In the absence of clear principles to guide business compliance, firms would be left to wait for a tap on the shoulder from the Consumer Interest Authority.

\subsubsection{Limited standard of review for CA98 enforcement cases}

The CMA complains that the CAT's merits reviews of its CA98 determinations are lengthy and over-burdensome, so should be replaced by judicial review (or a similar standard). The letter shows no appreciation of why determinations by staff-led CDGs from its enforcement directorate face a different standard of review to determinations by groups of independent Panel Members in its markets and mergers directorate. As discussed in section 2.2, the independence of decision-making behind the first instance determination should be a key factor in setting the appropriate standard of review.

A second factor is the seriousness of the consequences of the CMA's determination. For these, it is less clear that that there is more at stake from a civil breach of the CA98 prohibitions, than there is, at least potentially, from some of the remedies that may be imposed by market investigations. Breach of the prohibitions can result in a substantial fine, though fines rarely make a substantial dent in the financial health of the firm. Associated damages can also be high, though damages are intended only to return an ill-gotten gain. The quasi-criminality of breaching a prohibition can also be reputationally damaging, as well as being important under HRA98. While there are no fines following a market investigation, the range of potential remedies can have a very significant financial effect (e.g. price controls or the break-up of a firm). These can be imposed despite the absence of any breaches of the law. Such remedies are a major challenge to property rights, arguably requiring greater safeguards than fines following quasi-criminality.

Overall, there is a case for clarifying and rationalising the standards of review for CMA determinations, but this should not be done piecemeal and without reform of CMA decisionmaking.

\subsection{Coherent institutional reform for the CMA}

There are very serious challenges facing the CMA. It needs to have the institutional strength and confidence to restore public faith in markets and to address the turbulent competition landscape of digital markets, Brexit, Covid-19, and climate change.

The CMA has been very active in thinking about some of these new challenges, as well as appreciating the significance of behavioural consumers. Its portfolio of responsibilities, including leadership in consumer law alongside competition, is helpful for integrating the supply-side of markets (competition) and the demand-side (consumers). The skill set of the CMA also makes it the most appropriate institutional arrangement for reviewing the market effects of state aid, but there is no disputing the fact that proper execution of this role will test the relationship between the CMA and SoS. Finally on its mandate, it would be helpful to have a more appropriate primary duty, not for ungrounded 'consumer interest', but 'to

\footnotetext{
93 There is even a suggestion that the markets regime may be made "simpler and more effective" by removing phase 2 market investigation; (n 91) 14.
} 
promote effectively competitive markets for the benefit of consumers' or a similar wording that would be more inclusive of consumer law and its role in state aid.

Unfortunately, the current institutional narrative told by the CMA is to blame 'new forms of business behaviour' and the CAT appeals process for weaknesses in its own performance. It requests new powers at the same time as its current powers are under-used. It seems happiest operating through less formal market studies, making recommendations for regulation or actions for implementation by other bodies. Such recommendations eschew the requirement for rigorous evidence gathering, and avoid using the CMA's statutory powers with risk of the associated appeals processes. This is not healthy for an institution charged with implementing competition law. What should be done?

One alternative would be to change the system fundamentally from the current inquisitorial approach to one in which the CMA prosecutes cases before the CAT. This was seriously considered for CA98 cases in the review prior to ERRA13 and has been proposed by Nazzini as a response to the CMA's concerns in the Tyrie letter. ${ }^{94}$ It would be a completely new approach to case choice and development, and undoubtedly take many years to bed down. This would be a huge distraction from the current challenges, and it would leave unjustifiable differences between the prohibitions and merger and market investigations. Furthermore, there is no convincing evidence that a prosecutorial system would be a superior arrangement to a well-designed inquisitorial system. It would be better to reform the current, compromise and compromised institution. It might still be worth it if the current system was completely broken, but that is not the case.

Much of the problem derives from the way the CMA squeezed together the OFT and CC. If it had been designed from scratch, there would be a common approach to decision-making across the enforcement and markets and mergers directorates. The current differences are a historical artefact. In cases requiring similar economic analysis, and with similar effects on consumers and firms, there is no good reason to have different decision structures according to legal instrument. ${ }^{95}$ From this perspective, the challenge is to draw on the best of the two institutional traditions to create a common approach to determining cases.

All first instance determinations under CA98 and EA02 should be made by groups drawn exclusively from the independent Panel, with a mix of backgrounds including law and economics. For full independence, Panel Members should continue to be appointed for fixed terms without possibility of renewal. Each decision group should be selected independently by the Panel Chair who should not be a member of an executive committee, particularly of the CPC which initiates cases.

While this arrangement looks like the current decision-making for phase 2 mergers and market investigations, there should be a qualitative change in the distance between the decision group and investigation staff. Prior to the CMA, there were separate staff investigation teams in the OFT for phase 1 and in the CC for phase 2. One of the aims of

\footnotetext{
${ }^{94}$ BIS (n 10); Nazzini (n 10).

95 Price-fixing and market-sharing cartels are an exception because such agreements are per se illegal even if they have no economic effects.
} 
creating the CMA was to allow staff continuity for speed and efficiency of investigations. However, the institutional arrangements did not change sufficiently to balance the increased potential for confirmation bias. This requires a greater element of staff challenge by the decision group, and a reduced level of the group's control of the investigation. This applies equally to CA98 and EA02 cases. ${ }^{96}$

Parties should continue to have access to decision groups in hearings and, if appropriate, on site visits. Decision groups should be able to revise the first phase SO, or theories of harm for second phase mergers and market investigations, and request further evidence gathering or analysis from CMA staff. They should not be involved in the production of technical working papers but should fully consider and, if necessary, challenge CMA staff analysis. The current openness and publication of non-confidential evidence, analysis and decisions should be preserved.

There should similarly be a greater separation between the Panel and senior executive staff. Neither the Panel Chair nor Panel Members should sit on the Case and Policy Committee. A purely executive CPC would continue with its current role except it should withdraw from involvement once it has referred a case to the Panel Chair to select a phase 2 decision group. The common approach to phase 2 decision-making across directorates would result in a more neutral choice in case selection and legal instrument to address an identified competition problem. This would pave the way for a legislative change to remove the requirement for merits appeals in CA98 cases, other than for the level of fines, which do not lend themselves to remittal. ${ }^{97}$ The depth of review should then flex with the degree of regulatory intervention and penalty. The CMA Board might continue to decide on opening market studies and references for full market investigation, but any Panel Member on the Board, including the Panel Chair, should withdraw from all such case-specific discussions.

Finally, the distortionary Treasury target should be suspended pending the development of a credible methodology to estimate the value of its casework for precedent-setting and deterrence, and the value of its wider advocacy.

\section{Conclusion}

The OFT and the CC's predecessors were established at a time when their roles were essentially advisory for the Minister's determination, and few business practices were necessarily unlawful. There was consequently little role for appeals. Despite these common features, each institution was established at a different time and with very different decisionmaking. The DGFT was an executive decision-maker while the CC's predecessors were in the

\footnotetext{
${ }^{96}$ While this is close to Nazzini's option 2 [(n 10) 30], he offers this only hypothetically as a contrast to the staff dominated CDGs. He does not mention the current independent CMA Panel, or decision-making in the mergers and markets directorate. He only says, in passing, that EA02 determinations are subject to judicial review because they "do not involve a finding of liability but are of a regulatory or administrative nature"; (n 10) 4.

${ }^{97}$ A similar point was made in the Furman review of digital markets; Unlocking Digital Competition: Report of the Digital Competition Expert Panel, 2019, Recommended Action 14.
} 
spirit of a Royal Commission with a group leading an investigation and coming to a collective decision. Institutions evolve but they remain hostages to their historical roots.

CA98 and EA02 were transformative in the roles and responsibilities of the OFT and CC. Competition replaced public interest as the substantive test across the body of competition law. Anti-competitive agreements and the abuse of dominance were prohibited for the first time, and significant penalties for breach were introduced. The OFT and CC became determinative, with the SoS withdrawing from case determinations. The CAT provided an essential safeguard in the form of review for disputed decisions. The OFT, in particular, was slow to change its decision-making structures as its powers switched from being advisory and without firms being liable to penalties, to becoming determinative and with substantial financial liability for firms.

ERRA13 then squeezed the OFT and CC together into one organisation, the CMA, with the CC emerging in the markets and mergers directorate. Staff were combined, but there was no fundamental attempt to design an integrated approach to decision-making. The independence of CDGs in the enforcement directorate remains deeply compromised. The CMA also faces new challenges beyond its control. It needs to find the institutional strength and confidence to restore public faith in markets and to address the turbulent competition landscape of digital markets, Brexit, Covid-19, and climate change.

The CMA's response in the form of the Tyrie letter has been to request replacement of promotion of competition with an overriding consumer interest, to have new powers to threaten interim measures to cajole firms into doing what the CMA believes is in the consumer interest (without having to conduct an investigation), and to reduce the level of review by the CAT for enforcement decisions.

I have argued that the CMA needs to reform its own processes first. It is not necessary to go as far as taking determinations away from the CMA and requiring prosecution before the CAT. Much could be achieved by the enforcement directorate adopting the independent expert group decision-making currently used in the mergers and markets directorate, and creating more distance between such groups and staff investigators. Further reform of the Case and Policy Committee would more clearly separate first and second phase decisions and reduce distortions in the choice of legal instrument. It would then be appropriate to rationalise the standard of review. Despite numerous reorganisations and name changes, seventy years of history confirm how slowly institutional ways of working and decision-making procedures evolve. These straightforward proposals draw naturally on what has worked well in the past and would create a robust institutional foundation on which to build for a challenging future. 